\title{
Recria de borregas sob diferentes métodos de pastoreio em azevém anual em sucessão a lavoura
}

\author{
Stefani Macari(1), Paulo César de Faccio Carvalho(1), Lisandre de Oliveira ${ }^{(1)}$, Thais Devincenzi ${ }^{(1)}$, \\ Caetano Albuquerque ${ }^{(1)}$ e Aníbal de Moraes $^{(2)}$
}

\begin{abstract}
(1)Universidade Federal do Rio Grande do Sul, Faculdade de Agronomia, Avenida Bento Gonçalves, № 7.712, CEP 91540-000 Porto Alegre, RS. E-mail: stefanimacari@yahoo.com.br, paulocfc@ufrgs.br, liolivet@gmail.com, thais_devincenzi@yahoo.com.br, caetanoalbuquerque@gmail.com (2)Universidade Federal do Paraná, Departamento de Fitotecnia e Fitossanitarismo, Setor de Ciências Agrárias, Rua dos Funcionários, № 1.540, Cabral, CEP 80035-050 Curitiba, PR. E-mail: anibalm@ufpr.br
\end{abstract}

\begin{abstract}
Resumo - O objetivo deste trabalho foi avaliar a recria de borregas em pastagem de azevém anual (Lolium multiflorum) em sucessão a lavouras de milho ou soja, manejadas em intensidades de pastejo moderada ou baixa, com métodos de pastoreio rotativo ou contínuo. Utilizou-se o delineamento experimental de blocos ao acaso em arranjo fatorial 2 intensidades x 2 métodos de pastoreio, com quatro repetições. Não houve interação entre os métodos e as intensidades de pastejo. A intensidade de pastejo baixa determinou maior massa média de forragem e altura do pasto. A altura e a massa de forragem foram maiores no pastoreio rotativo. Não houve diferença para ganho médio diário. Houve diferença significativa para carga animal para o método rotativo e a intensidade de pastejo moderada. $\mathrm{O}$ ganho de peso por hectare foi maior para intensidade de pastejo moderada. A intensidade de pastejo e o método de pastoreio empregados não afetaram a produtividade de soja ou milho em sucessão. A forragem disponível é a principal determinante da produtividade do sistema integrado, independentemente do método de pastoreio.
\end{abstract}

Termos para indexação: Lolium multiflorum, pastoreio contínuo, pastoreio rotativo, sistema integração lavoura-pecuária.

\section{Rearing of lambs under different grazing methods on annual ryegrass in succession to crops}

\begin{abstract}
The objective of this work was to evaluate the rearing of lambs grazing on annual ryegrass (Lolium multiflorum) in succession with corn or soybean crops, managed at moderate or low grazing intensities, with rotational or continuous grazing methods. The experimental design used was randomized blocks in a factorial arrangement 2 intensities $\mathrm{x} 2$ grazing methods, with four replicates. There was no interaction between grazing intensities and methods. Low grazing intensity provided higher forage mass and sward height. Height and forage mass were higher in rotational grazing. There was no difference in average daily gain. There was significant difference in stocking rate for the rotational method and moderate grazing intensity. Gain per hectare was higher for moderate grazing intensity. Grazing intensity and grazing methods did not affect soybean or corn yields in succession. The forage available is the main determinant of yield of the integrated system, independently of the grazing method.
\end{abstract}

Index terms: Lolium multiflorum, continuous stocking, rotational stocking, integrated crop-livestock system.

\section{Introdução}

A produção de carne ovina pode ser uma alternativa de diversificação de produção e rentabilidade em regiões nas quais predomina a agricultura familiar. O sistema tradicional é adotado na maioria destas propriedades, por ser necessário manter baixos custos produtivos, e os ovinos são criados quase exclusivamente em pastagens nativas, com baixo investimento, ou em áreas marginais degradadas, com baixa produtividade.

Uma alternativa para maximizar a utilização da terra, bem como obter maior disponibilidade de forragens, é utilizar áreas de lavoura para semeadura de pastagens para uso com pecuária no inverno. Embora esta seja uma alternativa viável, para os produtores a presença dos animais afeta de forma negativa as propriedades do solo e a subsequente produtividade das culturas (Tracy \& Zhang, 2008).

O entendimento sobre a utilização desse recurso forrageiro é fundamental, especialmente quando o sistema incorpora a fase agrícola que o antecede. A integração lavoura-pecuária permite a melhor utilização de recursos e a diversificação de renda; no entanto, para que seja bem sucedida, é necessário

Pesq. agropec. bras., Brasília, v.46, n.10, p.1401-1408, out. 2011 
encontrar o equilíbrio entre a produção e a colheita de forragem. $\mathrm{O}$ controle da intensidade de pastejo e a escolha dos métodos de pastoreio são ferramentas de manejo que devem ser utilizadas, pois o pastoreio parece ser benéfico somente quando a intensidade de pastejo é controlada (Carvalho et al., 2010).

O ideal é prover a quantidade de forragem que satisfaça plenamente os requerimentos dos animais, além de criar condições que permitam a sustentabilidade do sistema (Barbosa et al., 2007).

O objetivo deste trabalho foi avaliar a recria de borregas em pastagem de azevém anual em sucessão a lavouras de milho ou soja, manejadas em intensidades de pastejo moderada ou baixa, com métodos de pastoreio rotativo ou contínuo.

\section{Material e Métodos}

O experimento foi conduzido na Estação Experimental Agronômica da Universidade Federal do Rio Grande do Sul, localizada no Município de Eldorado do Sul, RS, ( $30^{\circ} 05^{\prime} 22^{\prime \prime} \mathrm{S}, 51^{\circ} 39^{\prime} 08^{\prime \prime} \mathrm{W}$, a $46 \mathrm{~m}$ de altitude). O clima da região, conforme classificação de Köppen, é do tipo Cfa, subtropical úmido. O solo da área experimental é classificado como Argissolo Vermelho distrófico típico (Santos et al., 2006), com relevo levemente ondulado, sem restrições para cultivos anuais.

A área experimental, de aproximadamente 6 ha, vem sendo utilizada em integração lavoura-pecuária desde 2003, com soja (Glycine max (L.) Merr.) e milho (Zea mays L.) como cultura no verão.

$\mathrm{Na}$ fase pecuária, utilizou-se pastagem de azevém anual (Lolium multiflorum Lam.), estabelecida por ressemeadura natural. Foi realizada adubação de $300 \mathrm{~kg} \mathrm{ha}^{-1}$ de adubo na fórmula 5-20-20. Foram aplicados $90 \mathrm{~kg} \mathrm{ha}^{-1}$ de nitrogênio $(\mathrm{N})$, em cobertura, na forma de ureia, em uma única aplicação. O período experimental foi de 102 dias de utilização do pasto, com início do pastoreio em 2/8/2006.

Os tratamentos aplicados na pastagem corresponderam à combinação entre as intensidades de pastejo baixa e moderada e os métodos de pastoreio contínuo e rotativo. As intensidades de pastejo foram definidas por ofertas de forragem que representassem 2,5 (moderada) ou 5,0 (baixa) vezes o potencial de consumo diário de $4 \%$ do peso vivo (PV) (National Research Council, 1985).
Foram utilizados três borregas teste e número variável de borregas reguladoras por meio da técnica "put-and-take", para ajuste da oferta de forragem. O período de ajuste de carga para pastoreio contínuo foi o mesmo utilizado para pastoreio rotativo, por ser necessário buscar ofertas de forragem próximas para os dois métodos. Para definição do período de ajuste, foi utilizada duração de vida da folha como critério para duração dos ciclos de pastejo. O período de descanso foi definido a partir de uma variável morfogênica indicadora do intervalo ótimo de desfolhação, conforme Pontes et al. (2003), segundo a qual a duração de vida da folha é de $500^{\circ} \mathrm{C}$ por folha, em agosto, e $410^{\circ} \mathrm{C}$, de setembro a novembro. Esses valores foram divididos pela temperatura média de agosto a novembro, obtida a partir de séries climáticas do Setor de Agrometeorologia da Estação Experimental Agronômica da Universidade Federal do Rio Grande do Sul. O número de dias do ciclo de pastejo variou ao longo do ciclo e o período de ocupação foi fixado em dois dias, o que resultou em quatro ciclos de pastejo de 32, 26, 24 e 20 dias.

A utilização da pastagem teve início quando o azevém se encontrava em fase vegetativa avançada, em virtude do atraso na chegada dos animais ao experimento.

Foram utilizadas 147 borregas de nove meses das raças Texel, Suffolk e Ile de France, com peso médio inicial de $28 \pm 1,6 \mathrm{~kg}$. As pesagens dos animais foram realizadas no início e no final de cada ciclo de pastoreio, sendo respeitado um jejum prévio de 12 horas em todas as pesagens.

Para avaliar as condições metabólicas e nutricionais das borregas, foram coletadas, das três borregas avaliadoras em cada unidade experimental, amostras de sangue da veia jugular, mediante sistema "vacutainer", em tubos heparinizados (Becton Dickinson, São Paulo, SP), ao final de cada período experimental. As amostras foram acondicionadas em recipientes isotérmicos e encaminhadas ao laboratório, onde foram centrifugadas a $2.500 \mathrm{rpm}$, e as alíquotas de plasma foram congeladas a $-20^{\circ} \mathrm{C}$, até análise. Foram quantificados metabólitos representativos do metabolismo energético, proteico e mineral, com técnicas específicas de fotocolorimetria: glicose pelo método da glicose oxidase; beta-hidroxibutirato (BHB) pelo método cinético-enzimático ultravioleta; proteína total pelo método do Biuret; ureia pelo método da urease; e fósforo pelo método do molibdato de amônio. O cortisol também foi dosado como indicador 
de estresse, pelo método de radioimunoanálise em fase sólida, com kit reagente ICN (BC Biomedical Laboratories Ltd., Surrey, British Columbia, Canadá).

A oferta de forragem foi calculada com a seguinte fórmula: $\mathrm{OF}=(\mathrm{MF} / \mathrm{n}+\mathrm{TAD}) \times 100 / \mathrm{CA}$, em que: $\mathrm{OF}$, oferta de forragem (\%); MF, massa de forragem média de cada ciclo de pastoreio $\left(\mathrm{kg} \mathrm{ha}^{-1}\right.$ de matéria seca, MS); n, número de dias do ciclo de pastejo; TAD, taxa diária de acúmulo da forragem ( $\mathrm{kg} \mathrm{ha}^{-1}$ de MS); CA, carga animal média do ciclo de pastoreio $\left(\mathrm{kg} \mathrm{ha}^{-1} \mathrm{de}\right.$ PV).

A altura do pasto foi medida como a distância entre o solo e a lâmina foliar mais elevada na superfície do pasto, em 30 pontos por unidade experimental, com bastão graduado com medição em centímetros (Barthram, 1985).

Para obter a MF dos tratamentos em pastoreio contínuo, foram realizados seis cortes do pasto por unidade experimental em cada ciclo de pastoreio. Para piquetes em pastoreio rotativo, a MF foi avaliada por dois cortes na segunda faixa de pastoreio, no início do ciclo, e por dois cortes na penúltima faixa de pastoreio, no final do ciclo. A MF foi obtida pela média de quatro cortes avaliados por unidade experimental em cada ciclo de pastoreio. Todos os cortes foram feitos aleatoriamente em nível do solo, com auxílio de moldura metálica de $0,5 \times 0,5 \mathrm{~m}$. As amostras foram secas em estufa de ar forçado a $65^{\circ} \mathrm{C}$, até peso constante.

A estimativa da TAD no método de pastoreio contínuo foi realizada a cada ciclo de pastoreio, com três gaiolas de exclusão de pastejo por unidade experimental (Klingman et al., 1943) alocadas em pontos representativos da MF de cada piquete. $\mathrm{O}$ acúmulo de forragem em período correspondente a cada ciclo de pastejo foi cortado dentro de cada gaiola e seco em estufa para pesagem posterior, sendo utilizado procedimento idêntico ao descrito para obtenção da MF. Nos piquetes de pastoreio rotativo, a TAD foi avaliada a cada ciclo de vida da folha. No final de cada ciclo, amostras de forragem da segunda e da penúltima faixa de pastoreio foram cortadas, e a TAD foi obtida pela diferença dos valores dos cortes da MF residual.

A produção total de MS foi determinada pela soma da MF previamente acumulada até o início da aplicação dos tratamentos, com as produções de forragem obtidas a cada intervalo de avaliação (TAD multiplicado pelo número de dias de cada ciclo de pastejo).

O ganho médio diário (GMD), em quilograma por animal, foi obtido pela diferença entre os pesos iniciais e finais dos animais teste, dividida pelo número de dias do período experimental. $\mathrm{O}$ ganho de peso por área (GPA), expresso em quilograma por hectare de PV, foi obtido ao multiplicar-se a taxa de lotação média, em animais por hectare, pelo GMD dos animais teste e pelo número de dias de pastejo. A CA por período (ciclo de ajuste de oferta de forragem) foi calculada pela soma do peso médio dos animais teste com o peso dos animais reguladores, multiplicada pelo número de dias em que os animais permaneceram na pastagem.

A dessecação para a semeadura da soja e do milho na safra 2005/2006 foi realizada com $2.400 \mathrm{~g}$ do ingrediente ativo glifosato. A cultivar de soja BRS 154 inoculada e a cultivar de milho Pioneer 30A04 foram semeadas em espaçamento de $40 \mathrm{~cm}$, com 20 e 3 sementes por metro linear, respectivamente. Ambos os plantios foram realizados com semeadora adubadora de plantio direto modelo AS 11500 A (Vence Tudo, Ibirubá, RS), em 14/12/2005.

A colheita das culturas de soja e milho ocorreu em 6/6/2006. Para avaliação de produtividade, foram coletadas quatro amostras por unidade experimental, o que correspondeu ao corte de três linhas de $4 \mathrm{~m}$. Em seguida, foi feita contagem das plantas para obtenção da população. As amostras foram trilhadas em trilhadeira estacionária, limpas e secas em estufa de ar forçado a $65^{\circ} \mathrm{C}$, até umidade constante, para obtenção da produtividade de grãos corrigidos para $13 \%$ de umidade. No entanto, os dados obtidos na safra 2005/2006 não foram utilizados, uma vez que houve a debulha e perda de grãos de soja.

Para a safra de soja 2006/2007, foi realizada, em $12 / 12 / 2006$, semeadura da mesma área do ano anterior, com a mesma cultivar e metodologia de semeadura. A colheita ocorreu em 7/5/2007, e a amostragem para avaliação da produtividade seguiu o modelo utilizado previamente.

Foi utilizado o delineamento experimental de blocos ao acaso, em arranjo fatorial 2x2 (2 métodos de pastoreio $\mathrm{x} 2$ intensidades de pastejo), com quatro repetições. O critério de bloqueamento foi aplicado com base em experimento com doses de nitrogênio em azevém, no mesmo local, em 2001. Para dados referentes à produtividade de soja e milho, foi utilizado arranjo fatorial $2 \times 2 \times 2$ ( 2 métodos de pastoreio $\times 2$ intensidades de pastejo x 2 tipos de rotação), com quatro repetições. Na fase lavoura, foram integradas 
duas unidades testemunha contíguas, cujo azevém no inverno não era submetido a pastejo.

Os resultados foram submetidos às análises de variância e regressão, e as médias foram comparadas pelo teste de Tukey, a 5\% de probablidade. Foi utilizado o procedimento Mixed do SAS (SAS Institute, 2002).

\section{Resultados e Discussão}

Não houve interação entre as intensidades de pastejo e os métodos de pastoreio ( $p>0,05)$ em nenhuma das variáveis; portanto, seus efeitos foram analisados separadamente.

O manejo do pasto para adequada condução do experimento resultou em OF significativamente distinta nas intensidades de pastejo com 9 e $24 \%$ de PV, para intensidades moderada e baixa, respectivamente. A verificação de similaridade da OF entre os métodos de pastoreio contínuo e rotativo nas intensidades moderada (10,65 vs. $7,5 \%$ de PV) e baixa (27 vs. $20 \%$ de PV) também foi importante para uma adequada comparação entre ambos os métodos.

$\mathrm{O}$ atraso na entrada dos animais resultou em maior acúmulo de MF que o preconizado por Poppi (1983), ao observar que o consumo de forragem por cordeiros é maximizado em forrageiras temperadas com MF de $1.800 \mathrm{~kg} \mathrm{ha}^{-1}$ de MS. A maior MF foi acompanhada de alturas iniciais médias de $19 \mathrm{~cm}$. Em alturas elevadas, pode ocorrer diminuição da profundidade do bocado e aumento no tempo necessário para formação do bocado (procura e apreensão de lâminas verdes) (Carvalho et al., 2001). Ao aumentar a MF ofertada, há tendência de aumento nos movimentos manipulativos de apreensão e mastigação (Ungar, 1996) e diminuição no tempo total de pastejo. Em ambas as situações, pode haver diminuição no consumo de forragens. $\mathrm{Na}$ integração lavoura-pecuária, o pasto é conduzido em ofertas de forragem muito superiores ao manejo tradicional, pois elevadas massas de forragem são necessárias à cultura subsequente (Carvalho et al., 2004).

As intensidades de pastejo moderada e baixa resultaram em MF significativamente diferentes (Tabela 1). As MF registradas para pastoreio rotativo foram superiores às registradas para pastoreio contínuo. Barbosa et al. (2010) também encontraram maior MF em pastoreio rotativo e sugerem que esta diferença pode ter sido resultado do controle da frequência de desfolha no período de descanso pós-pastejo, característica inerente a este método de pastoreio. De acordo com os autores, é provável que o tempo programado para recuperação após pastoreio tenha produzido maior índice de área foliar nos tratamentos com pastoreio rotativo (Barbosa et al., 2010).

A condução dos tratamentos resultou em TAD significativamente diferentes entre as intensidades de pastejo e os métodos de pastoreio utilizados (Tabela 1). Os valores observados são inferiores aos obtidos na mesma área experimental por Barbosa et al. (2007) e resultaram em baixa produção de forragem. A produção média total de forragem foi significativamente diferente entre os métodos de pastoreio utilizados.

O manejo com base nas diferentes intensidades de pastejo resultou em diferentes alturas do pasto (Tabela 1). A altura do pasto é um parâmetro útil e mais aplicável que a MF para subsidiar o manejo correto da pastagem e as tomadas de decisões sobre ajustes na CA. No presente trabalho, para cada centímetro de aumento na altura do pasto, a MF era acrescida em torno de $100 \mathrm{~kg} \mathrm{ha}^{-1} \mathrm{de}$ MS (Figura 1). Valores semelhantes foram encontrados por Aguinaga et al. (2008) e Baggio et al. (2008), em pastagem de aveia-preta e azevém.

Pontes et al. (2004) afirmam que para otimização dos fluxos de biomassa deve-se manter a altura do pasto

Tabela 1. Matéria seca, taxa diária de acúmulo e produção total de forragem, em quilograma por hectare, e altura do pasto, em cm, de azevém anual pastejado por borregas sob diferentes métodos de pastoreio e intensidades de pastejo ${ }^{(1)}$.

\begin{tabular}{|c|c|c|c|c|}
\hline \multirow[t]{2}{*}{ Variável } & \multicolumn{2}{|c|}{ Intensidade de pastejo } & \multicolumn{2}{|c|}{ Método de pastoreio } \\
\hline & Moderada & Baixa & Contínuo & Rotativo \\
\hline Matéria seca & $2.187 \pm 131,7 b$ & $2.877 \pm 131,7 \mathrm{a}$ & $2.254 \pm 131,7 b$ & $2.811 \pm 131,7 \mathrm{a}$ \\
\hline Taxa diária de acúmulo & $17 \pm 4,2 \mathrm{~b}$ & $32 \pm 4,2 \mathrm{a}$ & $44 \pm 4,2 \mathrm{a}$ & $5 \pm 4,2 \mathrm{~b}$ \\
\hline Produção total & $4.873 \pm 400,5 b$ & $6.022 \pm 400,5 \mathrm{a}$ & $6.615 \pm 400,5 a$ & $4.279 \pm 400,5 b$ \\
\hline Altura do pasto & $17 \pm 0,5 b$ & $24 \pm 0,5 \mathrm{a}$ & $17 \pm 0,5 \mathrm{~b}$ & $24 \pm 0,5 \mathrm{a}$ \\
\hline
\end{tabular}

${ }^{(1)}$ Médias \pm erro padrão seguidas de letras iguais nas linhas, dentro de intensidade de pastejo e método de pastoreio, não diferem pelo teste de Tukey, a 5\% de probabilidade. 
entre 10 e $15 \mathrm{~cm}$, já que maiores GMD e GPA também são observados neste intervalo de altura.

Não houve interação significativa no GMD entre as intensidades de pastejo e os métodos de pastoreio com os períodos estudados. O GMD das borregas não foi diferente entre os tratamentos. O maior ganho foi verificado no octogésimo quarto dia de pastoreio, enquanto o menor desempenho individual foi observado no quadragésimo sétimo dia. Esta queda no GMD não era esperada no período inicial. Entretanto, nesta época (setembro), os animais apresentaram problemas sanitários, que foram solucionados, e retomaram desenvolvimento normal apenas no período subsequente.

Uma nova queda no desempenho foi observada a partir de outubro, o que coincidiu com o início da fase reprodutiva do azevém. A observação dos parâmetros sanguíneos, com determinação do perfil metabólico (Tabela 2), poderia ser um preditor de desempenho, expresso em alta relação com o GMD. No entanto, apenas a ureia mostrou alta correlação $(96,8 \%$; $<<0,05)$

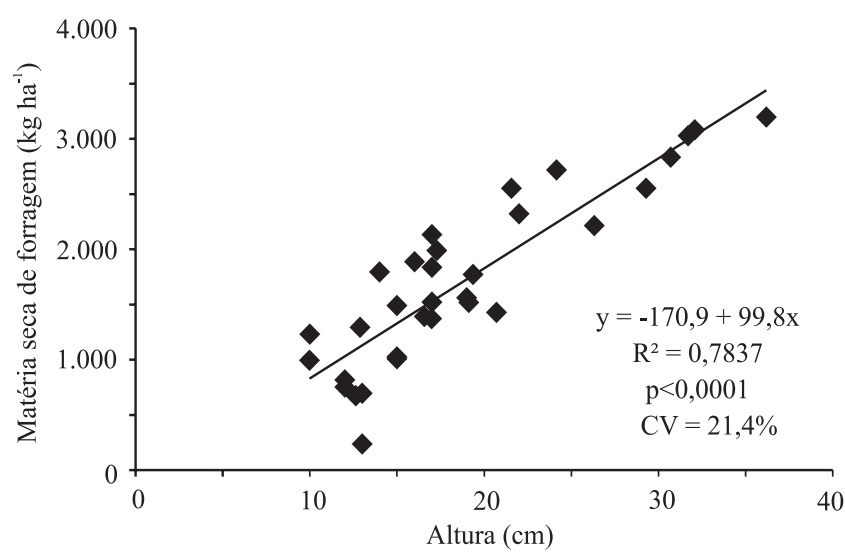

Figura 1. Relação entre matéria seca de forragem e altura do azevém pastejado por borregas sob diferentes métodos de pastoreio e intensidades de pastejo, e tipos de lavoura em sucessão. com o GMD, em que maiores ganhos acompanharam maiores concentrações de ureia plasmática. Maiores concentrações de ureia são percebidas quando há maior consumo de proteína na dieta, a qual diminui conforme o estadio fenológico da planta (Van Soest, 1994), o que é condizente com os menores GMD apresentados no final do período experimental quando o azevém se encontrava em fase reprodutiva avançada. Os resultados para GMD foram semelhantes aos observados por Canto et al. (1999), em pastagem de azevém anual consorciada com trevo-branco.

O menor nível de fósforo plasmático foi observado sob pastoreio rotativo com baixa intensidade de pastejo (Tabela 2). Apesar de o fósforo ser um bom indicador do status nutricional mineral de ovinos, González \& Schffer, (2003) e Cavalheiro \& Trindade (1992), em estudo sobre a disponibilidade de minerais para bovinos e ovinos em pastejo, perceberam que não há correlação entre a disponibilidade de fósforo da pastagem e o fósforo plasmático. Conforme os autores, as variações nos níveis plasmáticos de fósforo estão mais relacionados à demanda metabólica do que ao consumo mineral.

O cortisol associado ao stress, BHB (ligado à lipomobilização acentuada), bem como os demais parâmetros mensurados, não apresentaram diferença significativa nos tratamentos com animais em pastejo. Os valores observados estão dentro dos valores de referência para ovinos (González, 2000).

Mesmo sob alta intensidade de pastejo, a oferta de forragem foi suficiente para permitir desempenho apropriado, pois o peso final médio das borregas, de $42 \mathrm{~kg}$, está de acordo com o esperado. Segundo Sá \& Sá (2009), as fêmeas podem se reproduzir ao atingir a puberdade, em torno de 50 a $70 \%$ do PV adulto ou 30 a $50 \mathrm{~kg}$.

Na Figura 2, são apresentados os valores médios de CA. A CA utilizada no pastoreio rotativo foi $15 \%$

Tabela 2. Perfil metabólico de borregas pastejando azevém sob dois métodos de pastoreio (contínuo e rotativo) e duas intensidades de pastejo (moderada e baixa) ${ }^{(1)}$.

\begin{tabular}{|c|c|c|c|c|c|c|}
\hline Tratamento & Glicose & $\begin{array}{c}\text { Fósforo } \\
\left(\mathrm{mg} \mathrm{dL}^{-1}\right)\end{array}$ & Ureia & $\begin{array}{l}\text { Proteínas totais } \\
\qquad\left(\mathrm{g} \mathrm{L}^{-1}\right)\end{array}$ & $\begin{array}{c}\text { Cortisol } \\
\left(\mathrm{mcg} \mathrm{dL}^{-1}\right)\end{array}$ & $\begin{array}{c}\mathrm{BHB}^{(2)} \\
\left(\mathrm{mmol} \mathrm{L}^{-1}\right)\end{array}$ \\
\hline Contínuo/moderada & $63,9 \pm 5,1$ & $6,5 \pm 1,0 \mathrm{ab}$ & $48,8 \pm 6,0$ & $68,9 \pm 2,6$ & $2,8 \pm 0,3$ & $0,32 \pm 0,02$ \\
\hline Contínuo/baixa & $63,6 \pm 7,5$ & $6,2 \pm 0,4 \mathrm{ab}$ & $48,6 \pm 11,6$ & $64,7 \pm 1,9$ & $2,8 \pm 0,9$ & $0,29 \pm 0,03$ \\
\hline Rotativo/moderada & $67,7 \pm 8,4$ & $6,9 \pm 0,2 \mathrm{a}$ & $42,4 \pm 6,0$ & $68,4 \pm 2,2$ & $2,5 \pm 0,5$ & $0,25 \pm 0,03$ \\
\hline Rotativo/baixa & $64,6 \pm 7,5$ & $6,1 \pm 0,5 b$ & $42,6 \pm 2,6$ & $70,6 \pm 4,6$ & $2,0 \pm 0,2$ & $0,29 \pm 0,06$ \\
\hline
\end{tabular}

${ }^{(1)}$ Médias \pm erro-padrão seguidas de letras iguais não diferem pelo teste de Tukey, a $5 \%$ de probabilidade. ${ }^{(2)}$ Beta-hidroxibutirato. 
superior à utilizada no pastoreio contínuo. Os piquetes manejados sob intensidade de pastejo moderada suportaram CA 70,5\% superior aos manejados sob intensidade de pastejo baixa. Esta diferença foi consequência do manejo aplicado à pastagem, para manutenção das OF pretendidas, o que se refletiu em maior GPA (Figura 2), já que não houve diferença no GMD.

O GPA foi $64,7 \%$ maior para intensidade de pastejo moderada em comparação à baixa, e não houve diferença entre os métodos. Estes ganhos são superiores aos encontrados por Roman et al. (2007), em pastagem de aveia e azevém com borregos.

Em geral, quando a lotação utilizada é moderada, ocorre adensamento do solo; porém, não são afetados macro e micro porosidade nem desenvolvimento vegetal (Carvalho et al., 2005). Segundo esses autores, a compactação pode ocorrer em elevadas intensidades de pastejo, com comprometimento do crescimento das plantas. As lotações utilizadas no presente trabalho, aliadas à manutenção da altura da pastagem sempre acima de $10 \mathrm{~cm}$ (Tabela 1), podem ter ajudado a proteger o solo da ação do pisoteio, pois não houve diferença significativa na produtividade de grãos de milho e de soja da lavoura subsequente (Figura 3), com produtividade similar nas áreas sob diferentes intensidades e métodos. As áreas sem pastejo, em que a pastagem de inverno funciona apenas como cobertura vegetal e tem

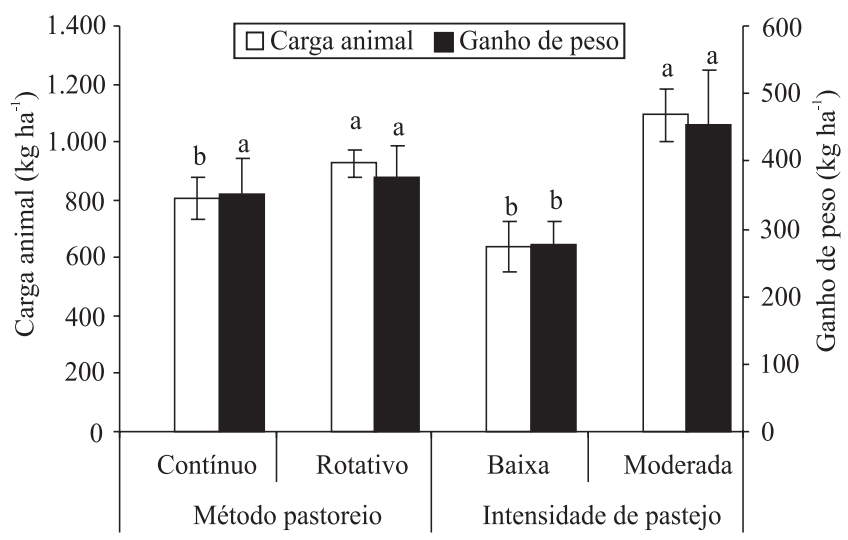

Figura 2. Carga animal e ganho de peso por área em pastagem de azevém anual pastejada por borregas sob diferentes métodos de pastoreio e intensidades de pastejo, em Eldorado do Sul, RS. Médias \pm erro-padrão seguidas de letras iguais, dentro de método de pastoreio e de intensidade de pastejo, para a mesma variável não diferem, pelo teste de Tukey, a 5\% de probabilidade. função de palhada para lavoura em sucessão, não produziram mais do que as áreas em pastoreio.

O plantio de milho foi realizado como mais uma fonte de diversidade, para maior sustentabilidade do sistema ILP. No entanto, não houve interação entre as áreas de plantio exclusivo de soja e as áreas com alternância da cultura de verão. A diversificação da cultura de verão não aumentou a produtividade de grãos, mas pode auxiliar na diversificação de renda.

Com base nos dados de produtvidade das lavouras de milho e de soja (Figura 3), é evidenciado que a produtividade não foi afetada pelo pastoreio de ovinos realizado na pastagem no período anterior às lavouras. Maior produtividade de soja em áreas sob baixa intensidade de pastejo por ovinos também foram obtidos por Lunardi et al. (2008).

A MF e a altura final da pastagem estão de certa forma integradas ao manejo que favoreceria a produtividade das lavouras subsequentes, o que foi observado em 2005, quando maiores massas de forragem residual se correlacionaram $(60,8 \%$; $\mathrm{p}<0,05)$ com a maior produtividade de soja. Esta relação não foi observada nos anos subsequentes, para as culturas de soja e milho. Diversos autores já evidenciaram a importância da manutenção de massa e alturas adequadas, pois em condições de elevada interceptação de radiação, a pastagem possui elevado crescimento de folhas e raízes, o que confere ao solo maior capacidade de suporte de carga, no caso do pisoteio, ou maior capacidade de

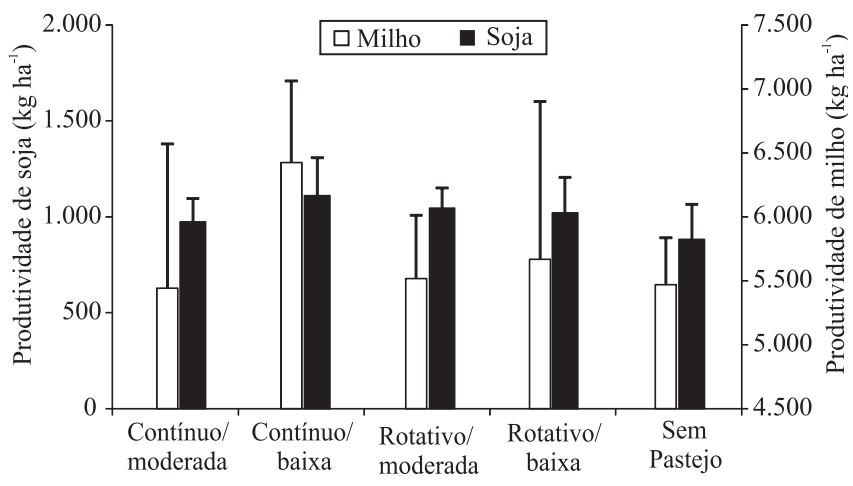

Figura 3. Efeito dos métodos de pastoreio (contínuo e rotativo) e das intensidades de pastejo (baixa e moderada) na fase pastagem sobre a produtividade de soja na safra 2006/2007 e de milho na safra 2005/2006, em sistema de integração lavoura-pecuária, em Eldorado do Sul, RS. Barras verticais referem-se ao erro-padrão da média. 
recuperação após eventual compactação (Tracy \& Zhang, 2008; Balbinot Junior et al., 2009). Assmann et al. (2003) observaram que a produtividade do milho aumentou linearmente de acordo com a quantidade de fitomassa seca deixada como resíduo de pastagem de inverno, quando não houve adição de $\mathrm{N}$ na cultura de milho.

\section{Conclusões}

1. O pastejo de borregas em pastagem de azevém em sistemas de integração lavoura-pecuária não prejudica a produção de soja e milho.

2. A intensidade de pastejo moderada em pastos de azevém determina aumento da produtividade animal por unidade de área.

3. O método de pastoreio, contínuo ou rotativo, não é determinante da produtividade animal e da subsequente produtividade de grãos de soja e milho.

\section{Referências}

AGUINAGA, A.A.Q.; CARVALHO, P.C. de F.; ANGHINONI, I.; PILAU, A.; AGUINAGA, A.J.Q.; GIANLUPPI, G.D.F. Componentes morfológicos e produção de forragem de pastagem de aveia e azevém manejada em diferentes alturas. Revista Brasileira de Zootecnia, v.37, p.1523-1530, 2008.

ASSMANN, T.S.; RONZELLI JÚNIOR, P.; MORAES, A.; ASSMANN, A.L.; KOEHLER, H.S.; SANDINI, I. Rendimento de milho em área de integração lavoura-pecuária sob o sistema plantio direto, em presença e ausência de trevo branco, pastejo e nitrogênio. Revista Brasileira de Ciência do Solo, v.27, p.675-683, 2003.

BAGgio, C.; CARVALHO, P.C. de F; SILVA, J.L.S. da; ROCHA, L.M. da; BREMM, C.; SANTOS, D.T. dos; MONTEIRO, A.L. Padrões de uso do tempo por novilhos em pastagem consorciada de azevém anual e aveia-preta. Revista Brasileira de Zootecnia, v.37, p.1912-1918, 2008.

BALBINOT JUNIOR, A.A.; MORAES, A. de; VEIGA, M. da; PELISSARI, A.; DIECKOW, J. Integração lavoura-pecuária: intensificação de uso de áreas agrícolas. Ciência Rural, v.39, p.1925-1933, 2009.

BARBOSA, C.M.P.; CARVALHO, P.C. de F.; CAUDURO, G.F.; LUNARDI, R.; GONÇALVES, E.N.; DEVINCENZI, T. Componentes do processo de pastejo de cordeiros em azevém sob diferentes intensidades e métodos. Archivos de Zootecnia, v.59, p.39-50, 2010.

BARBOSA, C.M.P., CARVALHO, P.C. de F; CAUDURO, G.F.; LUNARDI, R.; KUNRATH, T.R.; GIANLUPPI, G.D.F. Terminação de cordeiros em pastagens de azevém anual manejadas em diferentes intensidades e métodos de pastejo. Revista Brasileira de Zootecnia, v.36, p.1953-1960, 2007. Suplemento.
BARTHRAM, G.T. Experimental techniques: the HFRO sward stick. In: BARTHRAM, G.T. The hill farming research organization/biennial report. Penicuik: HFRO, 1985. p.29-30.

CANTO, M.W. do; MOOJEN, E.L.; CARVALHO, P.C. de F.; SILVA, J.H.S. da. Produção de cordeiros em pastagem de azevém e trevo branco sob diferentes níveis de resíduos de forragem. Pesquisa Agropecuária Brasileira, v.34, p.309-316, 1999.

CARVALHO, P.C. de F.; ANGHINONI, I.; MORAES, A. de; SOUZA, E.D. de; SULC, R.M.; LANG, C.R.; FLORES, J.P.C.; LOPES, M.L.T.; SILVA, J.L.S. da; CONTE, O.; WESP, C. de L.; LEVIEN, R.; FONTANELI. R.S.; BAYER, C. Managing grazing animals to achieve nutrient cycling and soil improvement in no-till integrated systems. Nutrient Cycling in Agroecosystems, v.88, p.259-273, 2010.

CARVALHO, P.C. de F.; ANGHINONI, I.; MORAES, A. de; TREIN, C.R.; FLORES, J.P.C.L.; CEPIK, C.T.C.; LEVIEN, R.; LOPES, M.T.; BAGGIO, C.; LANG, C.R.; SULC, R.M.; PELISSARI, A. O estado da arte em integração lavoura-pecuária. In: GOTTSCHALL, C.S.; SILVA, J.L.S.; RODRIGUES, N.C. (Org.). Produção animal: mitos, pesquisa e adoção de tecnologia. Canoas: Ulbra, 2005. p.7-44.

CARVALHO, P.C. de F.; CANTO, M.W.; MORAES, A. Fontes de perdas de forragem sob pastejo: forragens se perde? In: SIMPÓSIO SOBRE MANEJO ESTRATÉGICO DA PASTAGEM, 2., 2004. Viçosa. Anais. Viçosa: UFV, 2004. v.2, p.387-418.

CARVALHO, P.C. de F.; RIBEIRO FILHO, H.M.N.; POLI, C.H.E.C.; MORAES, A.; DELAGARDE, R. Importância da estrutura da pastagem na ingestão e seleção de dietas pelo animal em pastejo. In: REUNIÃO ANUAL DA SOCIEDADE BRASILEIRA DE ZOOTECNIA, 38., 2001, Piracicaba. Anais. Piracicaba: Sociedade Brasileira de Zootecnia, 2001. p.853-871.

CAVALHEIRO, A.C.L.; TRINDADE, D.S. Os minerais para bovinos e ovinos criados em pastejo. Porto Alegre: Sagra-DC Luzzato, 1992. 141p.

GONZÁLEZ, F.H.D. Uso do perfil metabólico para determinar o status nutricional em gado de corte. In: GONZÁLEZ, F.H.D; BARCEloS, J.O; OSPINA, H; RIBEIRO, L.A.O. (Ed.) Perfil metabólico em ruminantes: seu uso em nutrição e doenças nutricionais. Porto Alegre: UFRGS, 2000. p.63-74.

GONZÁLEZ, F.H.D.; SCHFFER, J.F.S. Perfil sangüíneo: ferramenta de análise clínica, metabólica e nutricional. In: SIMPÓSIO DE PATOLOGIA CLÍNICA VETERINÁRIA DA REGIÃO SUL DO BRASIL, 1., 2003, Porto Alegre. Anais. Porto Alegre: UFRGS, 2003. p.73-79.

KLINGMAN, D.L.; MILES, S.R.; MOTT, G.O. The cage method for determining consumption and yield of pasture herbage. Journal of American Society of Agronomy, v.35, p.739-746, 1943.

LUNARDI, R.; CARVALHO, P.C. de F.; TREIN, C.R.; COSTA, J.A.; CAUDURO, G.F.; BARBOSA, C.M.P.; AGUINAGA, A.A.Q. Rendimento de soja em sistema de integração lavoura-pecuária: efeito de métodos e intensidades de pastejo Ciência Rural, v.38, p.795-801, 2008.

MARASCHIN, G.E. Sistemas de pastejo. In: PEIXOTO, A.M.; MOURA, J.C. de; FARIA, V.P. (Ed.). Pastagens: fundamentos da exploração racional. Piracicaba: FEALQ, 1994. p.337-376. 
NATIONAL RESEARCH CONCIL. Nutrient requirement of sheep. $6^{\text {th }}$. ed. Washington: National Academy Press, 1985. 99p.

PONTES, L. de S.; CARVALHO, P.C. de F.; NABINGER, C.; SOARES, A.B. Fluxo de biomassa em pastagem de azevém anual (Lolium multiflorum Lam.) manejada em diferentes alturas. Revista Brasileira de Zootecnia, v.33, p.529-537, 2004.

PONTES, L. da S.; NABINGER, C.; CARVALHO, P.C. de F.; TRINDADE, J.K. da; MONTARDO, D.P.; SANTOS, R.J. dos. Variáveis morfogênicas e estruturais de azevém anual (Lolium multiflorum Lam.) manejado em diferentes alturas. Revista Brasileira de Zootecnia, v.32, p.814-820, 2003.

POPPI, D.P. Nutrition of the lamb after weaning. In: FAMILTON, A.S. (Ed.). Lamb growth. Hamilton: New Zealand Society of Animal Production, 1983. p.29-42.

ROMAN, J.; ROCHA, G.M. da; PIRES, C.C.; ELEJALDE, D.A.G.; KLOSS, M.G.; OLIVEIRA NETO, R.A. de. Comportamento ingestivo e desempenho de ovinos em pastagem de azevém anual (Lolium multiflorum Lam.) com diferentes massas de forragem. Revista Brasileira de Zootecnia, v.36,p.780-788, 2007.
SÁ, C.O. de; SÁ, J.L. Idade à primeira cria de borregas. 2000. Disponível em: <http://www.crisa.vet.br/exten_2001/borrega. htm>. Acesso em: 16 dez. 2009.

SANTOS, H.G. dos; JACOMINE, P.K.T.; ANJOS, L.H.C. dos; OLIVEIRA, V.A. de; OLIVEIRA, J.B. de; COELHO, M.R.; LUMBRERAS, J.F.; CUNHA, T.J.F. (Ed.). Sistema brasileiro de classificação de solos. 2.ed. Rio de Janeiro: Embrapa Solos, 2006. $306 \mathrm{p}$.

SAS INSTITUTE. Statistical analysis system user's guide. Version 9.0. Cary: SAS Institute, 2002.

TRACY, B.F.; ZHANG, Y. Soil compaction, corn yield response, and soil nutrient pool dynamics within an integrated crop-livestock system in Illinois. Crop Science, v.48, p.1211-1218, 2008.

UNGAR, E.D. Ingestive behaviour. In: HODGSON, J.; ILLIUS, A. (Ed.). The ecology and management of grazing systems. Wallingford: CAB International, 1996. p.185-218.

VAN SOEST, P.J. Nutritional ecology of the ruminant. $2^{\text {nd }}$ ed. New York: Cornell University Press, 1994. 475p.

Recebido em 30 de julho de 2010 e aprovado em 9 de agosto de 2011 